\title{
Evaluation of the Effectiveness of Erbium Lasers on Removing Calcium Hydroxide
}

\author{
Emre Culha ${ }^{1}\left(\mathbb{D}\right.$, Cihan Yildirim ${ }^{2}$ (D) \\ ${ }^{1}$ Akamer Oral and Dental Health Center, Mersin. \\ ${ }^{2}$ Uzmanlar Oral and Dental Health Clinic, Gaziantep. \\ Correspondence Author: Emre Culha \\ E-mail: emreculha@hotmail.com \\ Received: $14.05 .2020 \quad$ Accepted: 28.01.2021
}

\begin{abstract}
Objective: The purpose of this study was to compare the efficacy of Erbium, chromium-doped yttrium, scandium, gallium and garnet ( $\mathrm{Er}, \mathrm{Cr}: \mathrm{YSGG}$ ), and Erbium-doped yttrium aluminum garnet laser (Er:YAG) lasers with passive ultrasonic irrigation (PUI) and conventional syringe irrigation (CSI) for the removal of calcium hydroxide $\left[\mathrm{Ca}(\mathrm{OH})_{2}\right]$ paste from standardized canal irregularities.

Methods: Forty single-rooted human teeth were split longitudinally, forming halves, and cut a standardized groove in canal walls. After filling each groove with $\mathrm{Ca}(\mathrm{OH})_{2}$ paste, the teeth were reassembled and stored for 1 week. $\mathrm{Ca}(\mathrm{OH})_{2}$ was removed with $\mathrm{CSI}$ by using $10 \mathrm{milliliters}(\mathrm{mL})$ of $5 \%$ sodium hypochlorite $(\mathrm{NaClO})$ and $10 \mathrm{~mL}$ of $17 \%$ ethylenediaminetetraacetic acid (EDTA), respectively. The teeth were randomly divided into four groups $(n=10)$. CSI group was irrigated with10 $\mathrm{mL}$ of $5 \% \mathrm{NaClO}, 10 \mathrm{~mL}$ of $17 \%$ EDTA, and $10 \mathrm{~mL}$ of distilled water with CSI (control group), respectively. In Er:YAG group, 5\% NaClO was activated with Er:YAG laser, and in Er,Cr:YSGG group, Er,Cr:YSGG laser equipped with Radial Firing Tip 2 (RFT 2) was used. In the PUI group, PUI was used with 2.5\% NaClO. All groups received irrigation with $10 \mathrm{~mL}$ of distilled water as final irrigation. The root halves were examined with a stereomicroscope using a 4-grade scoring system.

Results: Residues of $\mathrm{Ca}(\mathrm{OH})_{2}$ in artificial grooves were observed in all groups. In Er,Cr:YSGG group, only three specimens got a score of 1 (less than half of the groove is filled). Er,Cr:YSGG group was found slightly higher yet the difference was found to be not significant with other groups.

Conclusions: Although Er,Cr:YSGG laser equipped with RFT 2 tip seems to have a superior effect on removing $\mathrm{Ca}(\mathrm{OH})_{2}$ from the standardized canal irregularities, there was no statistically significant difference between the applications.
\end{abstract}

Keywords: Er:YAG laser, Er Cr:YSGG laser, passive ultrasonic irrigation, artificial groove, calcium hydroxide

\section{INTRODUCTION}

Bacteria and their by-products contribute to pulpal and periapical pathologies (1). The elimination of microbiota at the root canal system can be achieved with the intervention of mechanical instrumentation, copious irrigation, and antibacterial medication. However, complex anatomy makes the entire disinfection of the root canal system impossible $(1,2)$.

Standard practice prefers calcium hydroxide $\left[\mathrm{Ca}(\mathrm{OH})_{2}\right]$ because of its antimicrobial properties against the majority of pathogens associated with endodontic lesions (3). Using $\mathrm{Ca}(\mathrm{OH})_{2}$ is an effective supplement to mechanical instrumentation. Also, because the tissue-dissolving ability of $\mathrm{Ca}(\mathrm{OH})_{2}$ allows remaining pulp tissue to be flushed away after the usage of $\mathrm{Ca}(\mathrm{OH})_{2}$ paste (4). Nevertheless, many studies suggest $\mathrm{Ca}(\mathrm{OH})_{2}$ is ineffective at eliminating pathogens in canal irregularities because of its low solubility and vulnerability to the neutralization of dental tissues.
Cleaning $\mathrm{Ca}(\mathrm{OH})_{2}$ paste before root canal filling is vital not only to prevent any undesired interactions between dressing and root canal sealer but also to ensure superior adhesion of the filling material to the root dentin. However, complete removal of $\mathrm{Ca}(\mathrm{OH})_{2}$ paste by using files and irrigating solutions exclusively is unfeasible (5). Research and practice have established various techniques in the field of $\mathrm{Ca}(\mathrm{OH})_{2}$ paste removal from the root canal system (6). The most widely used method is the utilization of the master apical file combined with conventional syringe irrigation (CSI) using $\mathrm{NaClO}$ and EDTA (7). Unfortunately, this technique may result in $\mathrm{Ca}(\mathrm{OH})_{2}$ residuals remaining particularly in irregularities of the apical region of the root canal due to the insufficient nature of CSI (8).

Passive ultrasonic irrigation (PUI) has been known to enhance the efficacy of irrigant delivery and augment root canal cleaning (9). Energy expansion resulting from an ultrasonically oscillating tip applied to the irrigant causes 
acoustical streaming and cavitational effects in the root canal (10). PUI performed after root canal preparation and before application of the master apical file allows the instrument to oscillate without constraint. Accordingly, the cutting action of the file is minimized and acoustic streaming and cavitation are more effective (11).

Laser-activated irrigation (LAI) is a promising procedure for root canal irrigation. The cleaning effect of LAI within the root canal results from rapid fluid motion provoked by expansion and implosion of laser-induced vapor bubbles at the fiber tip (12). The Erbium-doped yttrium aluminium garnet laser (Er:YAG) laser with an endodontic fiber tip effectively removes used $\mathrm{Ca}(\mathrm{OH})_{2}$, paste from the root canal without causing structural harm or anatomic changes inside the root canal or to periapical tissues (13). Studies have confirmed that using a plain fiber tip can impel an irrigation solution to the apical foramen without injurious effect on periapical tissues (14). This study aims to evaluate the efficacy of Erbium, chromium-doped yttrium, scandium, gallium and garnet (Er,Cr:YSGG), and Er:YAG lasers with passive ultrasonic irrigation and conventional syringe irrigation for the removal of $\mathrm{Ca}(\mathrm{OH})_{2}$ paste from standardized canal irregularities.

\section{METHODS}

This project was approved by the Ethics Committee of Gaziantep University in Gaziantep, Turkey (Application No: 2014-433). Forty single-rooted, noncarious maxillary human anterior teeth extracted for various reasons were selected. Only Vertucci type I teeth with a single canal were included and teeth with caries, resorptions, cracks, and immature apices were excluded. Buccolingual and mesiodistal radiographs were taken to confirm the existence of single canals without previous root canal treatment, variations in root canal configurations, resorption, or calcifications. Soft tissues and calculus were mechanically removed from root surfaces with the help of a periodontal scaler. The teeth were stored in distilled water at room temperature at the time of experimental procedures.

The crowns of the teeth were removed with a diamond disc (Horico, Berlin, Germany) underwater cooling to attain $13 \mathrm{~mm}$ a standard length and to eliminate variations in dimensions of the pulp chamber. The working length was adjusted by subtracting $1 \mathrm{~mm}$ from the length at which the tip of a size 10 K-file (Dentsply Maillefer, Ballaigues, Switzerland) was just visible. Revo-S rotary instruments were used (Micro-Mega, Besancon, France) for the root canal shaping process using the following sequence: SC1, SC2, and SU (size 25, 0.06 taper). A brushing motion with the SC1 file and a non-brushing action with the SC2 and SU were used until reaching the desired working length. The root canals were flushed with $1 \mathrm{~mL}$ of $5 \% \mathrm{NaClO}$ solution (Wizard; Rehber Kimya, Istanbul, Turkey) between each file change and applied a final flush using $2 \mathrm{~mL}$ of $17 \%$ EDTA and $2 \mathrm{~mL}$ of $5 \% \mathrm{NaClO}$, each for 1 minute (min).

\subsection{Preparation of Specimens}

The experimental root canal model is based upon the norm designed by Lee et al. and has been implemented in many studies analyzing the $\mathrm{Ca}(\mathrm{OH})_{2}$, paste removal $(6,9)$. All the roots in the study were grooved with a diamond disk longitudinally on the buccal and lingual surfaces along their long axis under water cooling and abstaining any penetration. Then the roots were split into two halves in a buccolingual direction with a hammer and chisel. The roots that could not be reassembled were rejected, retaining a total of forty specimens. To replicate an uninstrumented apical region, a longitudinal groove with nearly $4 \mathrm{~mm}$ length, $0.5 \mathrm{~mm}$ width, and $0.2 \mathrm{~mm}$ depth was cut into the root canal dentin of one half of each tooth at a distance of $2 \mathrm{~mm}$ to 6 $\mathrm{mm}$ from the apex (Fig 1). A customized ultrasonic tip was used (Dentsply Maillefer, Finland) with an ultrasonic device (EMS miniMaster Piezon; Nyon, Switzerland). After drying the halves with air and the grooves were filled with $\mathrm{Ca}(\mathrm{OH})_{2}$ paste (Best; Bem Dental Kimya Illaç San, İzmir, Turkey) with the help of paper points \#30-40 to replicate the occurrence of the retention of $\mathrm{Ca}(\mathrm{OH})_{2}$ paste to canal irregularities. Then root halves were reassembled with orthodontic latex elastics and all the gaps and the apical foramina were sealed with sticky wax to preclude the overflow of the irrigation solution and to achieve a vapor lock effect. After fixing the specimens in the Eppendorf vials (Fırat Plastik Kauçuk San, İstanbul, Turkey) with a silicone material (Optosil; Heraeus Kulzer, Hanau, Germany), the canals were temporarily sealed with cotton and temporary filling material (Cavit; Espe, Seefeld, Germany). The specimens were kept at $37^{\circ} \mathrm{C}$ with $100 \%$ humidity for a week to replicate an interappointment root filling. The specimens were divided into four groups $(n=10)$ at random, each defined by the respective irrigation techniques with which they would be treated (CSI, PUI, Er:YAG and Er,Cr: YSGG).

Figure 1. Schematic representations of the specimen preparation

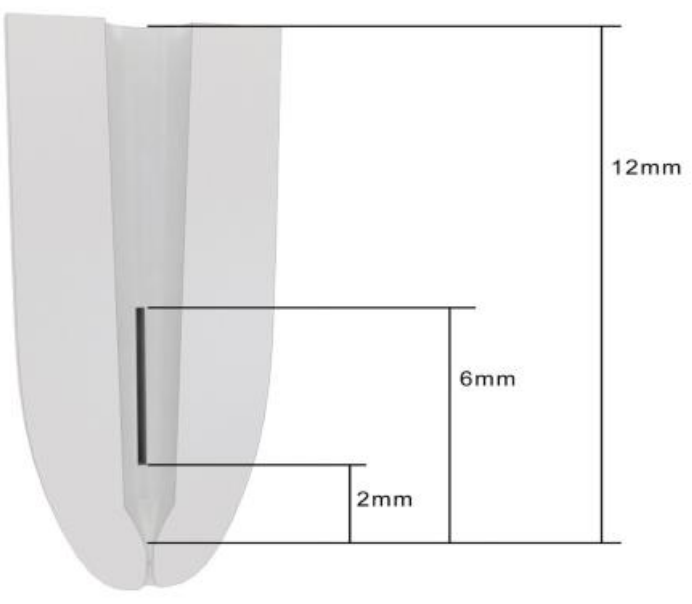

a. On one half of the instrumented root canal, a groove was cut 2 $\mathrm{mm}$ to $6 \mathrm{~mm}$ from the apex. 


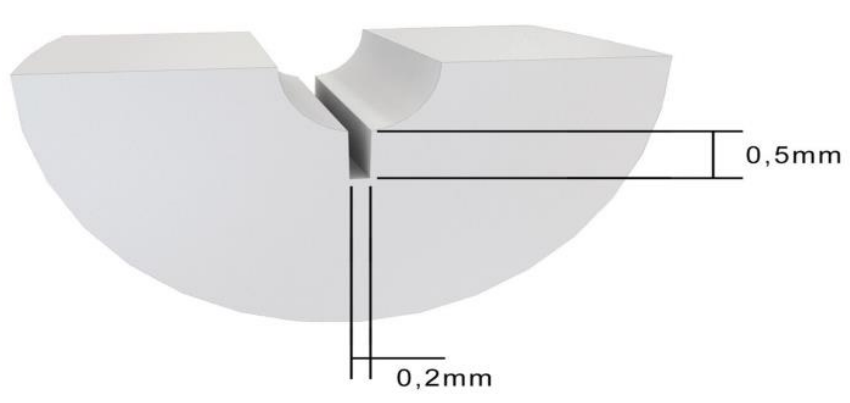

b. The groove was $0.5 \mathrm{~mm}$ depth and $0.2 \mathrm{~mm}$ wide.

For CSI group ( $n=10)$, hand irrigation with $10 \mathrm{~mL}$ of $5 \% \mathrm{NaClO}$, $10 \mathrm{~mL}$ of $17 \%$ EDTA, and $10 \mathrm{~mL}$ of distilled water, alternately, using a $10 \mathrm{~mL}$ syringe (Set Medikal, İstanbul, Turkey) with a 27-gauge needle was applied. The needle was inserted $1 \mathrm{~mm}$ above the working length and moved back and forth at the apical region for $20 \mathrm{~s}$.

In Er:YAG group ( $n=10)$ : Er:YAG laser system (Fidelis AT; Fotona, Ljubljana, Slovenia) was used with an R14 handpiece attached with a $300 \mu \mathrm{m}$ diameter and $14 \mathrm{~mm}$ flat fiber tip, (Preciso 300/14; Fotona, Ljubljana, Slovenia). The tip was inserted $5 \mathrm{~mm}$ above the working length and immobilized for $5 \mathrm{~s}$ at laser activation, repeated 4 times with $5 \mathrm{~s}$ intervals. When the irrigating solution in the coronal reservoir ran low, it was refreshed with $5 \% \mathrm{NaClO}$. The pulse energy measured at $50 \mathrm{~mJ}$ at $20 \mathrm{~Hz}$ and $50 \mu$ s super short pulse. The water and the air systems were turned off.

In Er,Cr:YSGG group ( $n=10)$ : Er,Cr:YSGG laser system (Iplus; Biolase, San Clemente, CA, USA) was equipped with a gold handpiece attached a $275 \mathrm{~mm}$ diameter and $21 \mathrm{~mm}$ length endodontic fiber tip (Radial Firing Tip 2; Biolase, San Clemente, CA, USA) were used at $1.25 \mathrm{~W}$ at $50 \mathrm{~Hz}$ in $\mathrm{H}$ mode. The settings were 34 for water and 24 for air. The fiber was held at $1 \mathrm{~mm}$ short of working length. This procedure was repeated 3 times by removing the tip in a continuous spiral motion at a rate of $1 \mathrm{~s}$ per mm. Researchers paused for $15 \mathrm{~s}$ between each exposure.

The specimens in the PUI group $(n=10)$ were activated by placing $0.5 \mathrm{~mL}$ of $5 \% \mathrm{NaClO}$ into the canal and performing passive agitation using an ultrasonic handpiece (Piezon miniMaster; EMS, Nyon, Switzerland). A flat ultrasonic file was placed (size 15 with 0.02 taper) (ESI instrument, EMS) into the canal $1 \mathrm{~mm}$ above the working length by avoiding to the root canal walls and allowing it to pulsate. After switching on the ultrasonic device, the intensity was set to the "Endo" mode. The file was activated for $20 \mathrm{~s}$ and repeated this procedure 3 times with 5 s intervals.

Following each irrigation procedure, the final irrigation of the root canals with $10 \mathrm{~mL}$ of distilled water was performed to avoid undesirable irrigant action.

\subsection{Digital Imaging and Scoring}

The specimens were dried with paper points. The roots were removed from the tubes to separate the halves. Stereomicroscope (Leica M165C; Leica Mycrosystem Ltd, Heerbrug, Germany) attached to a digital camera was used to obtain the images of the half of each canal with a groove at $20 \times$ magnification and transferred the images to a computer.

The amount of $\mathrm{Ca}(\mathrm{OH})_{2}$ paste in the grooves was evaluated according to the classification described by Van der Sluis et al

(6). The specimens were scored as follows:

- $\quad$ Score 0: The groove is empty (Fig. 2)

- Score 1: Less than half of the groove is filled with $\mathrm{Ca}(\mathrm{OH})_{2}$ (Fig. 3)

- Score 2: More than half of the groove is filled with $\mathrm{Ca}(\mathrm{OH})_{2}$ (Fig. 4)

- $\quad$ Score 3: The groove is filled with $\mathrm{Ca}(\mathrm{OH})_{2}$ (Fig. 5)

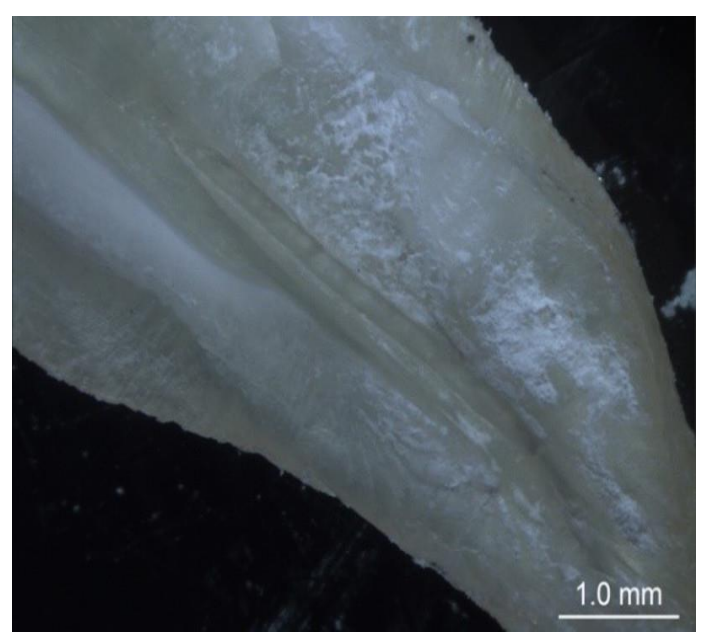

Figure 2. Score 0: The groove is empty.

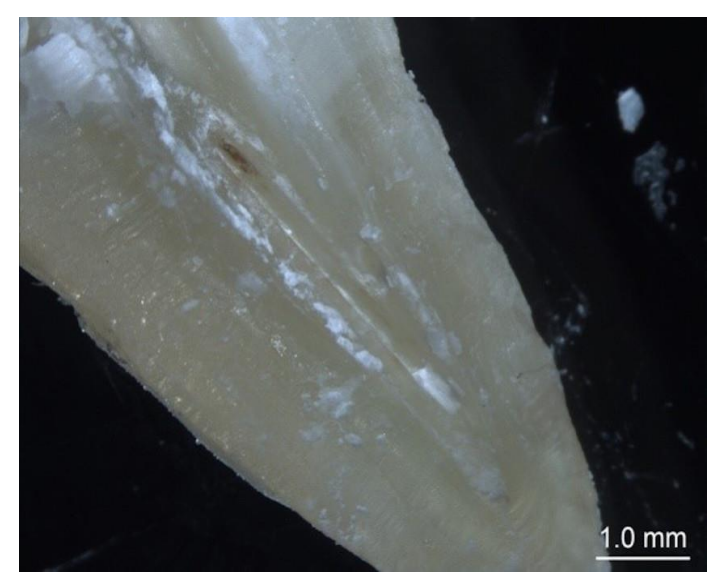

Figure 3. Score 1: Less than half of the groove is filled with $\mathrm{Ca}(\mathrm{OH})_{2}$. 


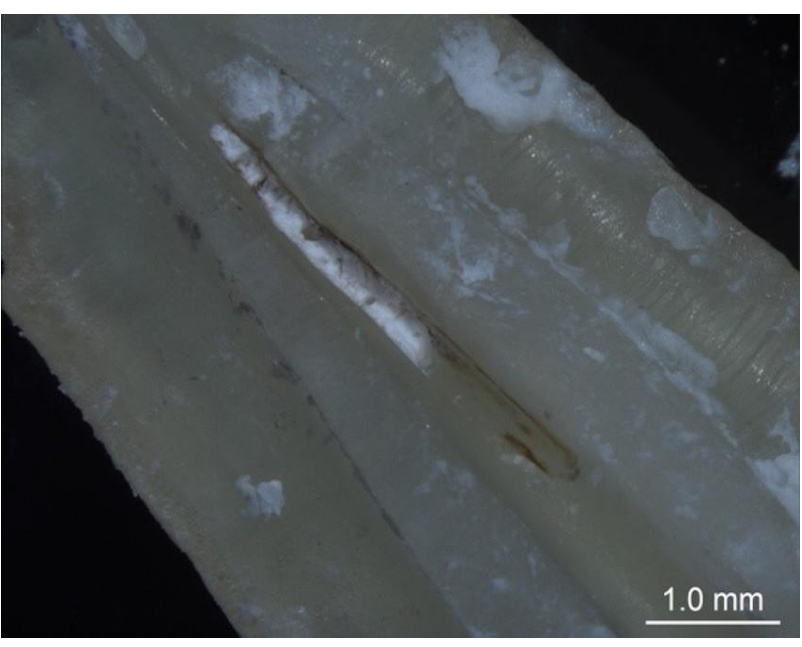

Figure 4. Score 2: More than half of the groove is filled with $\mathrm{Ca}(\mathrm{OH})_{2}$.

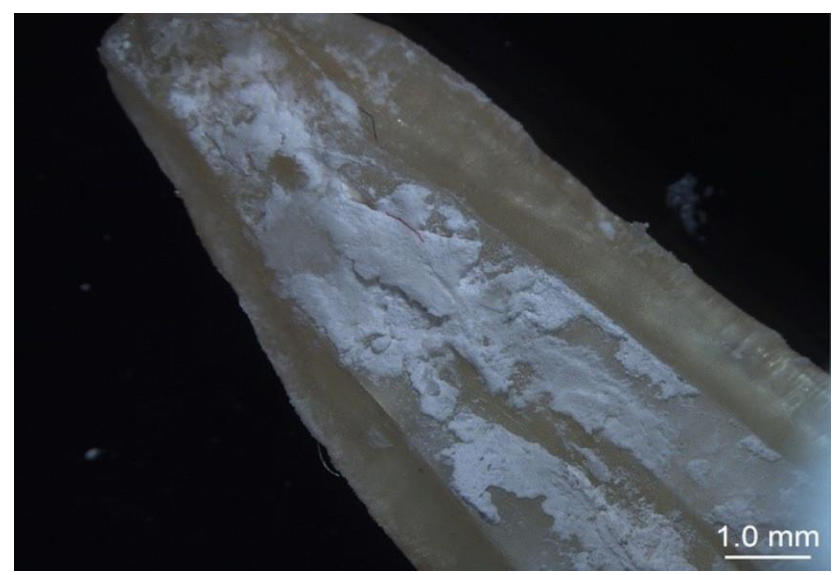

Figure 5. Score 3: The groove is filled with $\mathrm{Ca}(\mathrm{OH})_{2}$.

\subsection{Statistical Analysis}

The data was statistically analyzed by using nonparametric Kruskal Wallis test. The statistical analyses were performed by using software (IBM ${ }^{\circledR}$ SPSS $^{\circledR}$ Statistics 20; IBM SPSS Inc, Chicago, IL, USA).

\section{RESULTS}

Table 1 shows the numbers of scores after irrigation for each of the four different techniques. An overall significance was not detected among four groups with Kruskal Wallis test (Table 2). The score 0 ratio was the lowest in the CSI group (0\%). The highest score 0 ratio was seen in $\mathrm{Er}, \mathrm{Cr}$ : YSGG (70\%), then Er: YAG (60\%), lastly in PUI group (40\%). The highest Score 3 rate was in the CSI group (30\%). However, the analysis revealed no significant difference between PUI and the laser groups. None of the groups reported complete removal of $\mathrm{Ca}(\mathrm{OH})_{2}$ paste from the grooves. However, In $\mathrm{Er}, \mathrm{Cr}$ :YSGG group, there were slight $\mathrm{Ca}(\mathrm{OH})_{2}$ remnants as described in Score 1 only in 3 artificial grooves. Thus, the CSI group had the most remaining $\mathrm{Ca}(\mathrm{OH})_{2}$ paste.

Table 1. The scores of $\mathrm{Ca}(\mathrm{OH})_{2}$ removal

\begin{tabular}{|l|c|c|c|c|}
\hline Groups & Score 0 & Score 1 & Score 2 & Score 3 \\
\hline CSI & 0 & 3 & 4 & 3 \\
\hline PUI & 4 & 4 & 1 & 1 \\
\hline Er:YAG & 6 & 2 & 1 & 1 \\
\hline Er,Cr:YSGG & 7 & 3 & 0 & 0 \\
\hline
\end{tabular}

CSI: Conventional syringe irrigation; PUI: Passive ultrasonic irrigation; Er:YAG: Erbium-doped yttrium aluminum garnet laser; Er,Cr:YSGG: Erbium, chromium-doped yttrium, scandium, gallium and garnet

Table 2. Kruskal Wallis analysis of scores after $\mathrm{Ca}(\mathrm{OH})_{2}$ removal

\begin{tabular}{|l|c|c|c|c|}
\hline & CSI & PUI & Er:YAG & Er,Cr:YSGG \\
\hline $\begin{array}{l}25 \% \\
\text { Percentile }\end{array}$ & 0.75 & 1 & 1 & 1.25 \\
\hline Median & 3 & 2.5 & 1.5 & 2.5 \\
\hline $\begin{array}{l}75 \% \\
\text { Percentile }\end{array}$ & 3.75 & 4 & 5 & 3.75 \\
\hline Mean & 2.5 & 2.5 & 2.5 & 2.5 \\
\hline $\begin{array}{l}\text { Standard } \\
\text { Deviation }\end{array}$ & 1.732 & 1.732 & 2.38 & 1.291 \\
\hline
\end{tabular}

CSI: Conventional syringe irrigation; PUI: Passive ultrasonic irrigation; Er:YAG: Erbium-doped yttrium aluminum garnet laser; Er,Cr:YSGG: Erbium, chromium-doped yttrium, scandium, gallium and garnet

\section{DISCUSSION}

The Er:YAG laser-activated irrigation uses not only photoacoustic but also photomechanical properties, differentiating it from other activation methods. This technique uses sublative energy levels and short microsecond ( $\mu \mathrm{s})$ pulse rates $(50 \mu \mathrm{s})$, thus forming impulses that generate expansion and sequential shock waves inducing powerful streaming fluid and facilitating the 3-dimensional movement of irrigation solutions (15). Although the erbium lasers have the potential of thermal side effects such as carbonization and cracks in the root canal walls, using sublative parameters prevents these situations (16).

When water absorbs laser irradiation, the vapor bubble occurs and starts to expand (16). Matsumoto et al. presented evidence that this vapor bubble could increase in size to 1800 $\mu \mathrm{m}$ in $220 \mu \mathrm{s}$ when a $300 \mu \mathrm{m}$ laser tip was used, similar to the present study (12). Accordingly, they suggest that it is not essential to place the tip at the end of the canal because these bubbles are effective enough to clean entire of the root canal system, including the apical region. In the present study, this data was verified. By contrast with previous laser applications, flat Er:YAG laser tip inserted $5 \mathrm{~mm}$ short of the working length effectively removed $\mathrm{Ca}(\mathrm{OH})_{2}$ that was apically placed. This result can be clarified by the increase in fluid reaction kinetics resulting from laser activation. Therefore, new studies must be designed on the cleanness of the complete root canal system, including anastomoses and isthmuses (17). 
According to the results, the Er:Cr:YSGG showed considerable effect for $\mathrm{Ca}(\mathrm{OH})_{2}$ removal from a standard groove at the apical region. There were slight $\mathrm{Ca}(\mathrm{OH})_{2}$ remnants as described in Score 1 only in 3 artificial grooves. The impulsive disposition of laser-produced bubble formations may be the reason for this finding. Bubbles constitute the basis of cavitation. With every pulse, fluid is accelerated, and the acceleration causes inertial forces. By contrast, stabilized flow at CSI or PUI uses viscous stress (18). Besides, the direction of the laser light is toward the root canal walls for RFT in Er,Cr:YSGG, not to the apex of the root canal. As a result, the direct effect of the laser light also may have contributed to the cleanness of the artificial groove.

During the study, a spiral motion wasn't made in the irrigant in Er:YAG group, unlike previous methods that require exposure of the entire root canal wall straight to the laser light. Thus, the possibility of ledge formation appears to be much more with Er:YAG than with Er,Cr:YSGG (19). (16). Also, a distance of $5 \mathrm{~mm}$ above the working length was chosen for the place of the laser fiber tip in this study. Because it was demonstrated that there were two times as much dye penetration from the apical foramen by using fiber tip set at $4 \mathrm{~mm}$ than at $5 \mathrm{~mm}$ beyond the apical foramen.

Deleu et al. documented greater efficacy with the flat Er:YAG laser tip than with photon-initiated photoacoustic streaming concerning the removal of the smear layer (20). Studies have also demonstrated that lesser fiber diameters and higher pulse energies generate greater fluid flow and may increase the occurrence of vapor or a cavity containing bubbles at the irrigant (16). Additionally, bubbles generated in saltwater such as $\mathrm{NaClO}$ are prone to be more copious than in fresh water (21). This data may explain the efficacy of water and $\mathrm{NaClO}$ in PUI and LAl as irrigants.

All groups in the study produced cleaner artificial grooves compared to CSI. This finding confirms other studies focused on the efficacy of manual dynamic irrigation, PUI, and LAI with erbium lasers (21). Additionally, this study has documented that more artificially placed $\mathrm{Ca}(\mathrm{OH})_{2}$ is removed with PUI than with CSI. Data analysis indicated these results may result from the enhanced velocity and volume of solution flow during PUI.

It was shown that $4 \times 5 \mathrm{~s}$ repetitions of LAI with Er:YAG ended up with significantly fewer remnants in the artificial grooves than using PUI for $20 \mathrm{~s}$ (21). Contrary to this finding, there were no significant differences among the groups of the present study. This result can be explained with bigger pulse energy and lesser fiber diameter that produce stronger stream and cavitation. To evaluate erbium lasers on the removal of $\mathrm{Ca}(\mathrm{OH})_{2}$ paste from the root canals, further studies must be completed with recently designed tips, different application times, and types of $\mathrm{Ca}(\mathrm{OH})_{2}$ pastes, including anastomoses and isthmuses.

\section{CONCLUSION}

In this in vitro model, Er,Cr:YSGG maintained the entire cleaning of $\mathrm{Ca}(\mathrm{OH})_{2}$ paste from artificial grooves in most of the straight form root canals. Although there were slight $\mathrm{Ca}(\mathrm{OH})_{2}$ remnants only in 3 roots as described in Score 1, there was no difference between the applications. Besides, using erbium lasers for $20 \mathrm{~s}$ is as powerful as PUI for $3 \times 20 \mathrm{~s}$.

\section{Acknowledgments}

The authors deny any conflicts of interest. This study was supported by the Gaziantep University Scientific Research Projects Governing Unit.

\section{REFERENCES}

[1] Peters LB, Wesselink PR. Periapical healing of endodontically treated teeth in one and two visits obturated in the presence or absence of detectable microorganisms. Int Endod J 2002; 35:660-667.

[2] Siqueira JF, Jr, Araujo MC, Garcia PF, Fraga RC, Dantas CJ. Histological evaluation of the effectiveness of five instrumentation techniques for cleaning the apical third of root canals. J Endod 1997; 23:499-502.

[3] Siqueira JF, Jr, Lopes HP. Mechanisms of antimicrobial activity of calcium hydroxide: a critical review. Int Endod J 1999; 32:361-369.

[4] Meire M, De Moor R. Mineral trioxide aggregate repair of a perforating internal resorption in a mandibular molar. J Endod 2008; 34:220-223.

[5] Capar ID, Ozcan E, Arslan H, Ertas H, Aydinbelge HA. Effect of different final irrigation methods on the removal of calcium hydroxide from an artificial standardized groove in the apical third of root canals. J Endod 2014; 40:451-454.

[6] van der Sluis LW, Wu MK, Wesselink PR. The evaluation of removal of calcium hydroxide paste from an artificial standardized groove in the apical root canal using different irrigation methodologies. Int Endod J 2007; 40:52-57.

[7] Lambrianidis T, Kosti E, Boutsioukis C, Mazinis M. Removal efficacy of various calcium hydroxide/chlorhexidine medicaments from the root canal. Int Endod J 2006; 39:55-61.

[8] Burleson A, Nusstein J, Reader A, Beck M. The in vivo evaluation of hand/rotary/ultrasound instrumentation in necrotic, human mandibular molars. J Endod 2007; 33:782-787.

[9] Lee SJ, Wu MK, Wesselink PR. The effectiveness of syringe irrigation and ultrasonics to remove debris from simulated irregularities within prepared root canal walls. Int Endod J 2004; 37:672-678.

[10] van der Sluis LW, Wu MK, Wesselink PR. The efficacy of ultrasonic irrigation to remove artificially placed dentine debris from human root canals prepared using instruments of varying taper. Int Endod J 2005; 38:764-768.

[11] Roy RA, Ahmad M, Crum LA. Physical mechanisms governing the hydrodynamic response of an oscillating ultrasonic file. Int Endod J 1994; 27:197-207.

[12] Matsumoto $H$, Yoshimine $Y$, Akamine A. Visualization of irrigant flow and cavitation induced by Er:YAG laser within a root canal model. J Endod 2011; 37:839-843. 
[13] Guidotti R, Merigo E, Fornaini C, Rocca JP, Medioni E, Vescovi P. Er:YAG 2,940-nm laser fiber in endodontic treatment: a help in removing smear layer. Lasers Med Sci 2014; 29:69-75.

[14] Peeters HH, Mooduto L. Radiographic examination of apical extrusion of root canal irrigants during cavitation induced by Er,Cr:YSGG laser irradiation: an in vivo study. Clin Oral Investig 2013; 17:2105-2112.

[15] Kivanc BH, Ulusoy OI, Gorgul G. Effects of Er:YAG laser and $\mathrm{Nd}$ :YAG laser treatment on the root canal dentin of human teeth: a SEM study. Lasers Med Sci 2008; 23:247-252.

[16] De Moor RJ, Meire M, Goharkhay K, Moritz A, Vanobbergen J. Efficacy of ultrasonic versus laser-activated irrigation to remove artificially placed dentin debris plugs. J Endod 2010; 36:1580-1583.

[17] Rodig T, Sedghi M, Konietschke F, Lange K, Ziebolz D, Hulsmann M. Efficacy of syringe irrigation, RinsEndo and passive ultrasonic irrigation in removing debris from irregularities in root canals with different apical sizes. Int Endod J 2010; 43:581-589.

[18] de Groot SD, Verhaagen B, Versluis M, Wu MK, Wesselink PR, van der Sluis LW. Laser-activated irrigation within root canals: cleaning efficacy and flow visualization. Int Endod J 2009; 42:1077-1083.

[19] George R, Meyers IA, Walsh LJ. Laser activation of endodontic irrigants with improved conical laser fiber tips for removing smear layer in the apical third of the root canal. J Endod 2008; 34:1524-1527.

[20] Deleu E, Meire MA, De Moor RJ. Efficacy of laser-based irrigant activation methods in removing debris from simulated root canal irregularities. Lasers Med Sci 2015; 30(2):831-835.

[21] van der Sluis LW, Gambarini G, Wu MK, Wesselink PR. The influence of volume, type of irrigant and flushing method on removing artificially placed dentine debris from the apical root canal during passive ultrasonic irrigation. Int Endod J 2006; 39:472-476.

How to cite this article: Culha E, Yildirim C. Evaluation of the Effectiveness of Erbium Lasers on Removing Calcium Hydroxide. Clin Exp Health Sci 2021; 11: 47-52. DOI: 10.33808/clinexphealthsci.737154 